\title{
Implementing Project-Based Learning to Improve Students' Creative Disposition, Creativity and Understanding in Learning Light and Optics
}

\author{
Indah Laelasari Efendi ${ }^{1}$, Eka Cahya Prima ${ }^{2}$ \\ \{indah.laelasari@student.upi.edu ${ }^{1}$, ekacahyaprima@upi.edu ${ }^{2}$ \} \\ Universitas Pendidikan Indonesia, Bandung, Indonesia ${ }^{1,2}$
}

\begin{abstract}
The purpose of this research is to investigate the effect of implementing project-based learning on students' creative disposition, creativity, and understanding in learning light and optics. The method that was used in this research was experimental research. The result shows that creative disposition appears for 74.95 minutes of the total appearing time of five creative disposition indicators which is inquisitive, persistent, imaginative, collaborative and discipline. Then, the result of students' creativity was $69.73 \%$ which categorized as good. The result of the analysis of students' understanding, proves that there is an improvement in students' scores in learning light and optics after the implementation of project-based learning. This result can also be seen by the significant 0.001 which means there was an improvement in students' understanding. The recommendation of this research is to try to conduct the experiment on a different topic and compare the result in a control and experiment class.
\end{abstract}

Keywords: Project-Based Learning, Students ‘ Creative Disposition, Students` Creativity, Students' Understanding, Light and Optics.

\section{Introduction}

In the $21^{\text {st }}$ century, creativity is in high demand and has become one of the important elements that have to be developed by anyone willing to be literate and successful. Creativity is the core of what it is to be useful today [1]. The focus on the role of education as a place to explore and unlock students' creative potential to be creative and innovative is increasing [2]. Thus, creativity in school has to be developed to increase the number of successful and competitive students. Yet, in an educational framework, there is no fixed definition of creativity because different authors have defined different ways to explain creativity.

The potential advantage of trying to measure the increasing development of creativity in schools include the important aspect of the curriculum used in schools. Creative Learning can occur by improving motivation, alertness, concentration, achievement, and curiosity [3]. Thus, creative teaching can enhance and engage in creative learning.

Physics teachers usually more concerned about the formula and mathematical calculation rather than the emphasis on building strong conceptual knowledge. It is considered difficult because students need to deal with different representations such as formulas, calculations, conceptual explanations, experiments, and graphs at the same time [4]. Students have relatively a weak understanding of the main role of observing, investigating, and experimenting in science. Besides that many students get poor grades, lost interest, and 
negative attitudes toward physics in assumption to students perceived physics to be a very difficult, mathematical, and abstract subject [5].

Creative disposition is the characteristics of a creative person. There are five cores of creative disposition which include inquisitive, persistent, imaginative, collaborative, and discipline. These characteristics can be observed during the lesson [6]. One method to observe creative disposition is by direct class observation and recording the learning process by using camcorder [7]. This recording will help the researchers to analyze students' creative disposition because it can be replayed and reduced the possibility of missing the observation data. The software used to analyze students' creative disposition is called Videography.

As the answer to the problem above, Project-based learning is implemented in this research. Project-based learning offers the chance for students to explore and investigate more about learning physics. Project-based learning will engage students to learn the important information of knowledge and life-enhancing skills through a systematic inquiry learning and authentic questions to thoughtfully design a product by carrying the given tasks [8]. Besides, project-based learning will engage the students to explore and investigate the main questions, propose a new hypothesis, and to share and trying out new ideas.

Light and Optics is chosen because it represents the science concept that relates to our daily life. The content that is covered in this topic is based on the Cambridge syllabus which is the refraction of light and a thin converging lens. Students' creativity can be measured by the homemade projector that the students make during the lesson in which project-based learning is implemented.

According to the background, this research aims to improve students' creative disposition, creativity, and understanding of learning light and optics. This prior research will be conducted by designing and analyzing the lesson plan, students' learning journal, students worksheet, and the test instrument about students' creative disposition, creativity, and understanding in learning light and optics.

\section{Research Method}

The research method used in this research was the Weak Experiment method using one group research without classroom control. This method was used to analyze the interrelationship within the variables and investigate external factors that might influence the research result [9].

The design was used in this research is one group pretest and posttest design. This design can measure the impact of the treatment given before and after getting implemented in one group research subject. In this research, students were given a test to know their prior knowledge or pretest, implementation of project-based learning to make a homemade projector as a treatment to measure their creative disposition, creativity, and understanding, and after the treatment was finally conducted, the final posttest will be conducted.

The research was conducted in private Secondary School in Bandung Barat which applied the Cambridge Curriculum in the learning process. The population of this research was all of the $8^{\text {th }}$-grade students in the school. The sample is 26 of class X. The sampling technique is a purposive sampling technique. 


\section{Result and Discussion}

\subsection{Students' Creative Disposition}

In this research, the lesson plan was made through the preparation stages. The preparation stages are: analyzing the curriculum, determining the topic to be taught, and relates the lesson with the implementation of project-based learning. First, researchers analyze the Cambridge IGCSE Physics syllabus to determine the content needs to be covered and suitable to be implemented along with project-based learning to allow the students to have a better understanding of learning light and optics. Second, the researcher determines the topic light and optics be taught to the sample students. The researcher limits the concept into refraction of light and converging lens and the learning objectives in each meeting were set.

Students' creative disposition which is measured in this research involves the five creative disposition models which are inquisitive, persistent, imaginative, collaborative, and disciplined. The creative disposition in the lesson was observed directly by the researcher. The lesson was also recorded by using the camcorder to avoid missing data during the lesson. The software used to analyze the lesson is called Videography as seen in Figure 1.

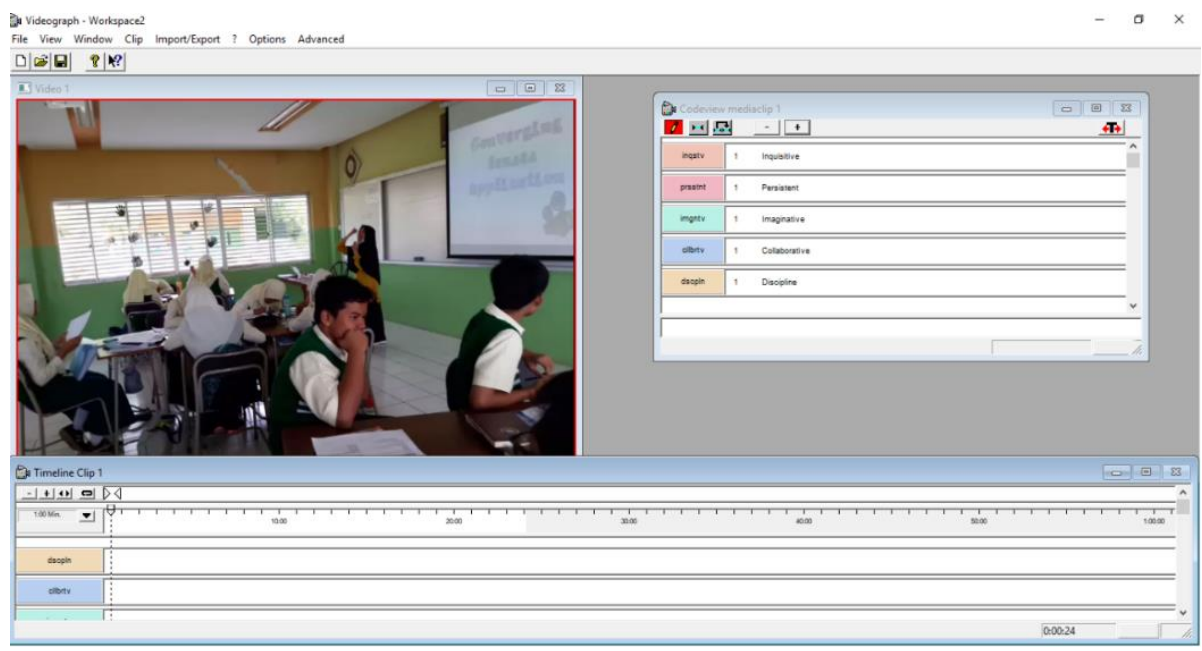

Fig. 1. Display of Video Analysis using Videography.

The recapitulation of students' creative disposition observed by recorded using camcorder during the lesson can be seen in Table 1.

Table 1. Recapitulation of Students' Creative Disposition.

\begin{tabular}{cccc}
\hline Meeting & No & Creativity Dimension & $\begin{array}{c}\text { Appearing Time } \\
\text { (Minutes) }\end{array}$ \\
\hline \multirow{3}{*}{$1^{\text {st }}$ Meeting } & 1 & Inquisitive & 4.22 \\
& 2 & Persistent & 3.37 \\
& 3 & Imaginative & 3.11 \\
& 4 & Collaborative & 1.29
\end{tabular}




\begin{tabular}{cccc}
\hline Meeting & No & Creativity Dimension & $\begin{array}{c}\text { Appearing Time } \\
\text { (Minutes) }\end{array}$ \\
\hline \multirow{5}{*}{$2^{\text {nd }}$ Meeting } & 5 & Disciplined & 1.00 \\
& 1 & Inquisitive & 3.28 \\
& 2 & Persistent & 4.59 \\
& 3 & Imaginative & 3.51 \\
& 5 & Collaborative & 5.03 \\
$3^{\text {rd }}$ Meeting & 1 & Disciplined & 2.19 \\
& 2 & Inquisitive & 3.42 \\
& 3 & Persistent & 4.01 \\
& 4 & Imaginative & 3.58 \\
& 5 & Collaborative & 5.46 \\
$4^{\text {th }}$ Meeting & 1 & Disciplined & 2.23 \\
& 2 & Inquisitive & 2.49 \\
& 3 & Persistent & 3.35 \\
& 4 & Imaginative & 3.57 \\
& 5 & Collaborative & 2.43 \\
& 1 & Disciplined & 2.02 \\
$5^{\text {th }}$ Meeting & 2 & Inquisitive & 3.46 \\
& 3 & Persistent & 4.06 \\
& 4 & Imaginative & 3.17 \\
& 5 & Collaborative & 6.03 \\
& & Disciplined & 2.09 \\
\hline
\end{tabular}

The result of students' creative disposition was observed during the lesson in which the Project-Based Learning was implemented. The result of each criterion that appeared during the lesson was varied. For the first meeting, inquisitive has the longest looking time, and discipline has the shortest appearing time. The collaborative has the longest emerging time in the second meeting, third meeting, and fifth meeting while the subject has the shortest appearing time in all five sessions. Students' persistence is increasing in the second meeting and fifth meeting as the students make the homemade projector.

\section{2 Students' Creativity Analysis}

Students' creativity is measured by using students' creative products. Creativity had been considered in terms of process or person [10]. The product that is assessed in this research is the homemade projector. In this research, students' creativity is measured after the implementation of project-based learning by using CPAM by Besemer and Treffinger [11].

The result shows that novelty is categorized as enough, while resolution and elaboration are categorized as good. This based on Arikunto of $63.33 \%$ for novelty, 71.07 for resolution, and $68 \%$ for elaboration and synthesis. The result and discussion will be presented to get more understanding about students' creativity in the following creativity dimension.

\subsection{Students 6 Understanding}

Students' understanding profile was collected by giving all students an objective test in the form of 24 multiple choice questions about Light and Optics. The questions consist of cognitive level C1 (remembering), C2 (Understanding), C3 (applying), and C4 (analyzing) distributed in the pretest and posttest. 
The level of significant value used in the test is 0.05 . the result of the test shows that the significant value is 0.001 or less than 0.05 which means there is a difference in students' understanding in learning light and optics after the implementation of Project-Based Learning or there is a significant effect. The average score of students' understanding of pretest and posttest is shown in Figure 2.

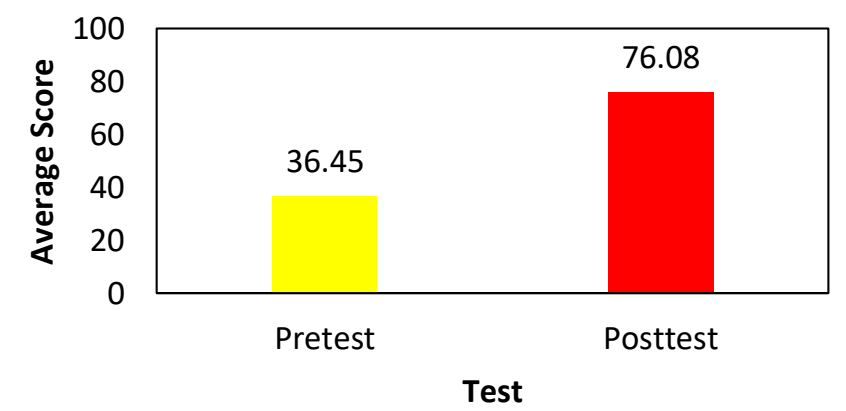

Fig. 2. The average score of Students` Understanding.

It can be seen that the average score of the pretest is 36.45 and the average posttest is 76.08. It means that there is an improvement in students' understanding of learning light and optics after the implementation of Project-Based Learning.

The recapitulation for each cognitive level N-Gain is presented in Figure 3.

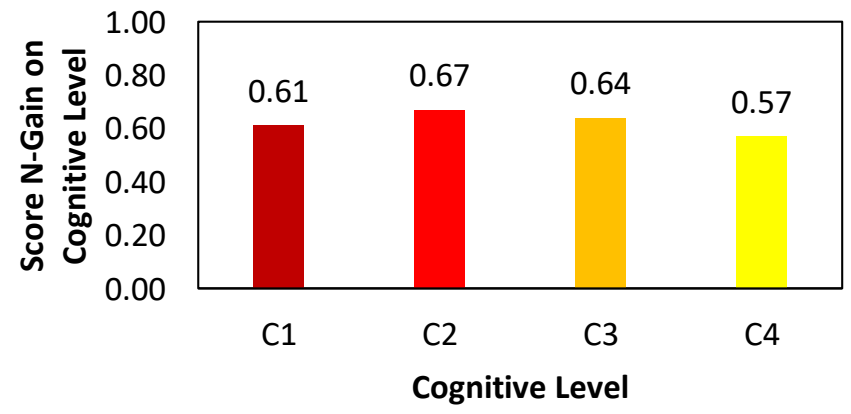

Fig. 3. Recapitulation of Cognitive Level of Bloom's Taxonomy.

It can be seen that each cognitive domain shows different results of students' understanding of pretest and posttest. The result shows that the average N-Gain on remembering $(\mathrm{C} 1)$ is 0.61 which categorized as medium. The average $\mathrm{N}$-Gain on understanding $(\mathrm{C} 2)$ is 0.66 which categorized as medium. The average N-Gain on applying (C3) is 0.63 which can be categorized as a medium, and the average N-Gain on analyzing (C4) is 0.56 which can be categorized as medium. Based on this result, the data can support the fact that students can more comprehend the topic after the implementation of Project-Based Learning. 


\section{Conclusion}

The conclusions of the Implementing Project-Based Learning to Improve Student's Creative Disposition, Creativity, and Understanding in Learning Light and Optics are the implementation of Project-Based Learning can improve students' creative disposition in learning light and optics. This can be seen from the result of video analysis that these five criteria of creative disposition by Lucas, Claxton, and Spencer (2014) have appeared during the lesson. It can improve students' understanding of learning light and optics. This result can be seen from the improvement of students' scores during the pretest and posttest.

Based on the findings of the research that has been concluded, there are several suggestions that necessary to be undertaken by the researcher, some of them are It is important to consider the composition of the group. The group should consist of both low ability and high ability students. Time allocation for accomplishing the project should be considered and determined correctly so that the students can achieve it optimally, and to try to conduct the experiment on a different topic and compare the result in a control and experiment class.

\section{References}

[1] Sternberg, R. J.: The nature of creativity. Creativity Research Journal, 18(1) (2006).

[2] Craft, A.: Creative development in the early years: some implications of policy for practice. Curriculum Journal, 10(1), pp. 135-150 (1999).

[3] Torrance, E. P.: Creative teaching makes a difference. Creativity: Its Educational Implications. Dubuque, IA (1981).

[4] Zubairu, K.: The role of professional education in developing compassionate practitioners: A mixed methods study exploring the perceptions xof health professionals and pre-registration students (2014).

[5]Krajcik, J. S., \& Blumenfeld, P. C.: Project-based learning, pp. 317-34. (2006).

[6] Lucas, B., Claxton, G., and Spencer, E.: Progression in Student Creativity in School: First Steps towards New Forms of Formative Assessments. Contemporary Readings in Law and Social Justice. 6(2), 81-121 (2014).

[7] Widodo, A. \& Ramdaningsih, V.: Analisis Kegiatan Praktikum Biology Dengan Menggunakan Video. Jurnal Metalogika: Bidang Kependidikan MIPA. 9(2). pp.148-158 (2006).

[8] Mahmudi, A. Project Based Learning.: Southeast Asian Ministers of Education Organization(SEAMEO), Regional Centre for Quality Improvement of Teachers and Educational Personal (QITEP) in Mathematics. Material of Course on Joyful Learning in Mathematics for Primary School Mathematics Teacher, Yogyakarta 2-22 Juli 2011 (2011).

[9] Fraenkel, J. R., Wallen, N. E., and Hyun, H. H.: How to Design and Evaluate Research in Education. New York: McGraw-Hill Education (2011).

[10] Barron, F., \& Harrington, D. M. Creativity, intelligence, and personality. Annual review of psychology, 32(1), pp. 439-476 (1981).

[11] Besemer, S. P., \& Treffinger, D. J.: Analysis of Creative Products: Review and Synthesis*. The Journal of Creative Behavior, 15(3), pp. 158-178 (1981). 